\title{
Awake prone position reduces work of breathing in patients with COVID-19 ARDS supported by CPAP
}

Davide Chiumello $0^{1,2,3^{*}} \mathbb{0}$, Elena Chiodaroli', Silvia Coppola', Simone Cappio Borlino², Claudia Granata², Matteo Pitimada ${ }^{2}$ and Pedro David Wendel Garcia ${ }^{4}$

\begin{abstract}
Background: The use of awake prone position concomitant to non-invasive mechanical ventilation in acute respiratory distress syndrome (ARDS) secondary to COVID-19 has shown to improve gas exchange, whereas its effect on the work of breathing remain unclear. The objective of this study was to evaluate the effects of awake prone position during helmet continuous positive airway pressure (CPAP) ventilation on inspiratory effort, gas exchange and comfort of breathing.
\end{abstract}

Methods: Forty consecutive patients presenting with ARDS due to COVID-19 were prospectively enrolled. Gas exchange, esophageal pressure swing ( $\triangle P$ Pes), dynamic transpulmonary pressure (dTPP), modified pressure time product (mPTP), work of breathing (WOB) and comfort of breathing, were recorded on supine position and after $3 \mathrm{~h}$ on prone position.

Results: The median applied PEEP with helmet CPAP was 10 [8-10] $\mathrm{cmH}_{2} \mathrm{O}$. The $\mathrm{PaO}_{2} / \mathrm{FiO}_{2}$ was higher in prone compared to supine position (Supine: 166 [136-224] mmHg, Prone: 314 [232-398] mmHg, $p<0.001$ ). Respiratory rate and minute ventilation decreased from supine to prone position from 20 [17-24] to 17 [15-19] b/min $(p<0.001)$ and from $8.6[7.3-10.6]$ to $7.7[6.6-8.6] \mathrm{L} / \mathrm{min}(p<0.001)$, respectively. Prone position did not reduce $\triangle P$ Pes (Supine: $-7[-9$ to - 5] $\mathrm{cmH}_{2} \mathrm{O}$, Prone: -6 [- -9 to -5$] \mathrm{cmH}_{2} \mathrm{O}, p=0.31$ ) and dTPP (Supine: 17 [14-19] $\mathrm{cmH}_{2} \mathrm{O}$, Prone: 16 [14-18] $\mathrm{cmH}_{2} \mathrm{O}$, $p=0.34)$. Conversely, mPTP and WOB decreased from 152 [104-197] to 118 [90-150] $\mathrm{cmH}_{2} \mathrm{O} / \mathrm{min}(p<0.001)$ and from 146 [120-185] to 114 [95-151] $\mathrm{cmH}_{2} \mathrm{O} \mathrm{L/min}(p<0.001)$, respectively. Twenty-six (65\%) patients experienced a reduction in WOB of more than 10\%. The overall sensation of dyspnea was lower in prone position $(p=0.005)$.

Conclusions: Awake prone position with helmet CPAP enables a reduction in the work of breathing and an improvement in oxygenation in COVID-19-associated ARDS.

Keywords: Continuous positive airway pressure, Awake prone position, Helmet CPAP, ARDS, COVID-19, Work of breathing

*Correspondence: davide.chiumello@unimi.it

${ }^{1}$ Department of Anesthesia and Intensive Care, ASST Santi Paolo E Carlo,

San Paolo University Hospital, Via A. di Rudinì 8, Milan, Italy

Full list of author information is available at the end of the article

\section{Background}

The SARS-CoV-2 infection can result in coronavirus 2019 disease (COVID-19). The clinical spectrum of COVID-19 can range from mild to critical forms of acute respiratory distress syndrome (CARDS, COVID19-associated ARDS) with an associated in-hospital mortality of up to $84 \%[1,2]$. Non-invasive and invasive mechanical ventilation have been reportedly employed 
in up to 62 and 36\%, respectively, of the critically ill COVID-19 patients requiring respiratory support [24]. Similarly to classic ARDS, the clinical management of CARDS is intended to provide a lung protective strategy enabling adequate gas exchange and limiting damage to the lung (i.e., ventilation induced lung injury (VILI)) [5].

In the early phase of the pandemic, based on previous, positive studies on the use of prone position in ARDS [6, 7], international scientific societies recommended the use of prone position in moderate to severe mechanically ventilated CARDS $[8,9]$. The use of prone position in mechanically ventilated CARDS patients significantly improved the oxygenation without any major changes in lung compliance $[10,11]$. Recently, prone position has been employed in non-invasively mechanically ventilated CARDS patients ("awake prone position") to improve oxygenation [12-15]. However, in the absence of data regarding its effect on endotracheal intubation rate and mortality, no firm recommendations have been issued on the use of awake prone position [8,16-18].

In addition to severe hypoxemia, CARDS suffering patients are characterized by an increased respiratory rate and inspiratory effort that in turn can promote patient self-inflicted lung injury (PSILI) [19]. Non-invasive respiratory support, especially in the form of helmet CPAP, has been suggested to reduce the inspiratory effort and possibly, the requirement of invasive mechanical ventilation [20-22]. Awake prone position, employed synergistically with non-invasive respiratory support, has been hypothesized to result in a decrease of inspiratory effort, dyspnea and lower rates of intubation, by promoting better lung inflation and recruitment $[12,15,17,23]$.

In light of the scarcity of data regarding the benefits of awake prone position concomitant to non-invasive respiratory support in CARDS, we aimed to evaluate the effect of awake prone position in helmet CPAP ventilated patients by comparing it to supine position regarding the reduction of inspiratory effort, the improvement in gas exchange and comfort of breathing.

\section{Methods \\ Study population}

All adults ( $>18$ years), presenting with a laboratoryconfirmed SARS-CoV-2 infection and suffering acute hypoxemic respiratory failure with a $\mathrm{PaO}_{2} / \mathrm{FiO}_{2}$ ratio $<300 \mathrm{mmHg}$ under application of a PEEP $\geq 5 \mathrm{cmH}_{2} \mathrm{O}$ by means of helmet CPAP, displaying bilateral ground glass opacities on chest X-ray or computed tomography (CT) of the lung, admitted to the high dependency unit of the ASST Santi Paolo e Carlo Hospital, Milan, Italy from February to April 2021 were enrolled. Patients were excluded in case they required immediate endotracheal intubation, presented unstable hemodynamics or had a Glasgow Coma Scale $<15$.

The study was approved by the institutional review board of the ASST Santi Paolo e Carlo Hospital (protocol number 0008332) and informed consent was obtained according to Italian regulations. The study has been registered on ClinicalTrials.gov.

\section{Study design}

At hospital admission every patient received a CT of the lung at atmospheric pressure (Fig. 1).

CPAP was delivered through a high flow generator (VitalSigns inc., Totowa, USA; $90-140 \mathrm{~L} / \mathrm{min}$; Myo 3133A, Pulmodyne), using a helmet (Starmed, Italy). PEEP within the helmet was maintained between 7.5 and $10 \mathrm{cmH}_{2} \mathrm{O}$ through an adjustable mechanical valve and $\mathrm{FiO}_{2}$ was titrated to maintain a $\mathrm{SpO}_{2}>94 \%$.

When required to improve collaboration, patients received light sedation/analgesia with continuous infusion of morphine titrated between 10 and $20 \mathrm{mg} / 24 \mathrm{~h}$ and/or hydroxyzine titrated between 50 and $100 \mathrm{mg}$ three times a day (150-300 mg/24 h), and haloperidol, in case of delirium, titrated between $0.5 \mathrm{mg}$ four times a day

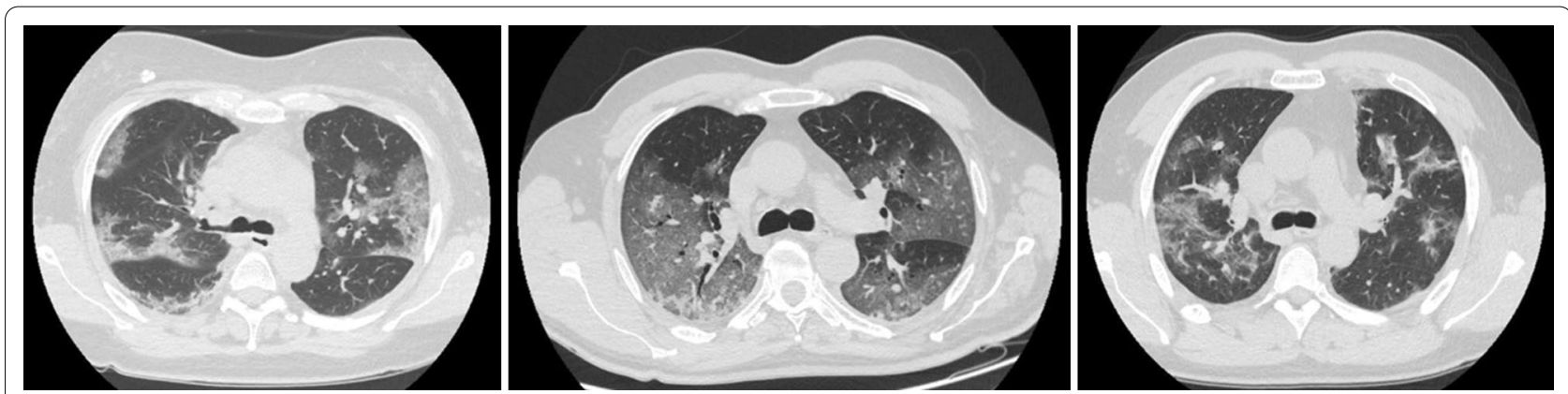

Fig. 1 Lung Computed Tomography. Lung Computed Tomography images (at the level of the carina), extracted from lung CT of three different patients, representative of the ARDS severity of the study population 
and $2 \mathrm{mg}$ six times a day $(2-12 \mathrm{mg} / 24 \mathrm{~h})$. The sedation was already started at study enrollment in supine position and the level of sedation (i.e., amount of used drugs) was not changed throughout the study, among supine and prone position.

At enrollment, a standard balloon catheter was positioned to measure the esophageal pressure (Nutrivent, SIDAM Italy) and a single-use padset sensor was placed on chest to measure respiratory volumes (ExSpiron 1Xi system, Respiratory Motion Inc., Inspired Innovation, Watertown, MA). On supine position and after $3 \mathrm{~h}$ from the initiation of prone position, arterial blood gas analysis, hemodynamics and esophageal pressure swings were assessed. The tidal volume, respiratory rate and minute ventilation were measured and breathing comfort was evaluated.

\section{Data collection}

Patient's demographic data and the most relevant clinical characteristics were recorded at study entry. HACOR and Charlson score were also computed [24, 25].

To measure the esophageal pressure a standard balloon catheter, consisting of a $108 \mathrm{~cm}$ long tube with a $10 \mathrm{~cm}$ long walled balloon, was positioned in the lower section of the esophagus. The esophageal catheter was emptied of air and introduced transorally into the esophagus to reach a depth of between 45 and $55 \mathrm{~cm}$ measured from the mouth. Subsequently the balloon was inflated with $4 \mathrm{ml}$ of air [26]. The amount of gas in the balloon was periodically checked throughout the experiment. The esophageal pressure was measured by the OptiVent ${ }^{\mathrm{TM}}$ monitor (Sidam S.R.L., Modena, Italy), a device for the automated management of the esophageal catheter.

The tidal volume, respiratory rate and minute ventilation were measured by the ExSpiron $1 \mathrm{Xi}$ system. This system employs a bioelectrical impedance technique and consists of a single-use PadSet sensor placed on the chest [27].

The presence of dyspnea was evaluated on the basis of the "Borg perceived dyspnea" scale [28]. Patients were asked "how short of breath are you?" according to a scale from 0 to 10, zero indicating no shortness of breath and ten an extremely severe dyspnea (Additional file 1: Fig. S1). Patients were instructed on the appropriate use of the scale before the beginning of the protocol.

The non-invasive work of breathing was objectively evaluated by an independent physician according to a dedicated scale for COVID-19 patients, ranging from 1 to 7 , considering the respiratory rate, the presence of nasal flaring and the use of sternocleidomastoid as well as abdominal muscles [29].

Patients were followed until hospital discharge, the occurrence of intubation and/or death were recorded.

\section{Data analysis}

A quantitative CT scan analysis was performed. The total lung gas volume, weight, and the proportions of the respective inflation compartment (not inflated, poorly inflated, well inflated and over inflated) were computed as previously described [30].

Breath patterns were continuously recorded for 3-5 min, then analyzed and the results averaged for each study period.

As surrogate measure for the inspiratory effort the esophageal pressure swing ( $\Delta$ Pes), that is the maximal negative inspiratory deflection of esophageal pressure during the inspiration, was used. In addition, the dynamic transpulmonary pressure (dTPP) during the inspiration, that is the maximal difference between the airway pressure and esophageal pressure, the modified pressure time product (mPTP), computed as the product of $\triangle$ Pes and respiratory rate, and the work of breathing (WOB), calculated as the product of tidal volume, respiratory rate and the dynamic transpulmonary pressure, were used as inspiratory effort surrogate measures $[20,22]$. For the computation of the dynamic transpulmonary pressure (dTPP), the airway pressure was not measured, as it was assumed to be equal to the applied external PEEP by the mechanical valve of the helmet [31]. Dynamic lung compliance was computed as the quotient between tidal volume and $\Delta$ Pes. The chest wall elastance had to be neglected due to the impossibility to perform an airway occlusion maneuver in a spontaneously breathing patient.

The ventilatory ratio and the estimated dead space fraction were computed according to previously described equations (Additional file 1: Annex S1).

\section{Endpoints}

The main endpoint was the change in work of breathing from supine to prone position, whereas changes in oxygenation and comfort of breathing represented secondary endpoints.

\section{Statistical analysis}

A sample size of 40 patients was chosen given the mechanistic design of this study, in accordance to similar investigations having studied non-invasively mechanically ventilated patients [20, 22, 32]. Differences in studied lung mechanics and blood gas analytics between supine and prone position were studied employing a linear mixed effects model analysis. As independent variable fixed effect, supine/ prone position was entered into the model. As random effects, intercepts for subjects were employed. P values were calculated using a likelihood ratio test of the full model, with the effect in question, 
against a "null model", without the effect in question. P values for fixed effects were obtained by Satterthwaite's method. Differences between supine and prone position for categorical variables were studied by means of Fisher's exact test, as pertinent. Bivariate correlation analyses were performed employing Pearson, Spearman's or Kendall's correlation, as appropriate. Statistical analysis was performed via a fully scripted data management pathway using the $\mathrm{R}$ environment for statistical computing version 4.1.0. A two-sided $p<0.05$ was considered statistically significant. Values are given as medians with interquartile ranges or counts and percentages as appropriate, while individual variable effects between supine and prone position are reported as mean difference with $95 \%$ confidence intervals $(\mathrm{CI})$.

\section{Results}

Forty patients suffering from CARDS and supported with helmet CPAP were enrolled in the study. The main baseline characteristics are shown in Table 1. Patients were mainly of male sex $(65 \%)$, presented a median age of 59 [53-68] years, a body mass index of 27 [25-31] kg/ $\mathrm{m}^{2}$ and had a median of 2 [1-3] comorbidities, of which arterial hypertension was the most prominent $(40 \%)$. They were admitted to the hospital 6 [5-10] days after symptom onset. Helmet CPAP and prone position were started after 2 [2-4] days from hospital admission. All patients received the first pronation at the time of enrollment and were able to maintain the prone position consecutively for $3 \mathrm{~h}$.

The applied PEEP with helmet CPAP was 10 [8-10] $\mathrm{cmH}_{2} \mathrm{O}$ with a $\mathrm{PaO}_{2} / \mathrm{FiO}_{2}$ ratio of 166 [136-224] mmHg. At admission the quantitative lung CT scan showed a median lung weight and gas volume of 1112 [903-1291] $\mathrm{g}$ and 3282 [2698-3721] $\mathrm{ml}$, respectively. The amount of non-aerated lung tissue corresponded to 11 [8-17] $\%$, while the well-aerated tissue was 52 [43-62] \% of the total lung tissue (Fig. 1, Additional file 1: Table S1).

\section{Gas exchange}

Gas exchange data in supine and prone position are shown in Table 2. The $\mathrm{PaO}_{2} / \mathrm{FiO}_{2}$ was higher in prone position compared to supine (Supine: 166 [136-224] mmHg, Prone: 314 [232-398] mmHg, $p<0.001)$. Thirtyfour $(85 \%)$ patients had an improvement in $\mathrm{PaO}_{2} / \mathrm{FiO}_{2}$ higher than $20 \%$, corresponding to a mean rise of 138 [95\% CI 108-169] mmHg, from supine to prone position. The change in oxygenation from supine to prone position was not related to the oxygenation in supine (Fig. 2). The baseline CT scan was not associated with the degree of oxygenation improvement (Additional file 1: Figs. S10-S13).
Table 1 Demographics and baseline characteristics of the study population

\begin{tabular}{|c|c|}
\hline & $\begin{array}{l}\text { Total population } \\
N=40\end{array}$ \\
\hline Age, years & 59 [53-68] \\
\hline Male sex & $26(65)$ \\
\hline Body mass index, $\mathrm{kg} / \mathrm{m}^{2}$ & $27[25-31]$ \\
\hline Charlson comorbidity index & $2[1-3]$ \\
\hline Arterial hypertension & $16(40)$ \\
\hline Diabetes mellitus & $5(12)$ \\
\hline Solid tumor & $4(10)$ \\
\hline Immunosoppression & $2(5)$ \\
\hline HACOR score at study start & $3[0-4]$ \\
\hline SOFA score at study start & $3[2,3]$ \\
\hline SAPS II score at study start & 24 [22-27] \\
\hline Time from symptoms to hospital admission, days & $6[5-10]$ \\
\hline $\begin{array}{l}\text { Time from hospital admission to CPAP and proning, } \\
\text { days }\end{array}$ & $2[2-4]$ \\
\hline C-reactive protein, $\mathrm{mg} / \mathrm{L}$ & $60[42-102]$ \\
\hline D-dimers, $\mu \mathrm{g} / \mathrm{L}$ & $371[248-575]$ \\
\hline Lactate, mmol/L & $1.3[1.0-1.4]$ \\
\hline \multicolumn{2}{|l|}{ ARDS classification } \\
\hline Mild & $14(35)$ \\
\hline Moderate & $22(55)$ \\
\hline Severe & $4(10)$ \\
\hline $\mathrm{PaO}_{2} / \mathrm{FiO}_{2}$ ratio, $\mathrm{mmHg}$ & $166[136-224]$ \\
\hline $\mathrm{PaO}_{2}, \mathrm{mmHg}$ & $114[90-141]$ \\
\hline $\mathrm{PaCO}_{2}, \mathrm{mmHg}$ & $38[35-42]$ \\
\hline PEEP, $\mathrm{cmH}_{2} \mathrm{O}$ & $10[8-10]$ \\
\hline Dynamic lung compliance $\left[\mathrm{ml} / \mathrm{cmH}_{2} \mathrm{O}\right]$ & $64[42-89]$ \\
\hline Requirement for endotracheal intubation & $7(18)$ \\
\hline Mortality at 28 days & $4(10)$ \\
\hline
\end{tabular}

HACOR Heart Rate, Acidosis, Consciousness, Oxygenation, Respiratory Rate, SOFA Sequential Organ Failure Assessment, SAPS II Simplified Acute Physiology Score, CPAP continuous positive airway pressure, ARDS acute respiratory distress syndrome, PEEP positive end-expiratory pressure

Data are presented as counts (percentages) for dichotomous values or median [interquartile range] for continuous values unless otherwise specified

Arterial carbon dioxide slightly increased between supine and prone position. The ventilatory ratio and the estimated physiological dead space decreased from supine to prone position (Table 2, Additional file 1: Figs. S2 and S3).

\section{Respiratory parameters, work and comfort of breathing}

The respiratory rate and minute ventilation decreased from supine to prone position from 20 [17-24] to 17 [15-19] $1 / \mathrm{min}$ and $8.6[7.3-10.6]$ to $7.7[6.6-8.6] \mathrm{L} / \mathrm{min}$, respectively (Table 2 ).

The prone position did not have any effect on $\Delta$ Pes $(p=0.306)$ and dTPP $(p=0.34)$ (Table 3). Conversely, 
Table 2 Respiratory mechanics and gas exchange of the study population during supine position and prone position

\begin{tabular}{|c|c|c|c|c|}
\hline & $\begin{array}{l}\text { Supine } \\
N=40\end{array}$ & $\begin{array}{l}\text { Prone } \\
N=40\end{array}$ & $p$ & Mean difference ${ }^{\dagger}[95 \% \mathrm{Cl}]$ \\
\hline Respiratory rate, bpm & 20 [17 to 24] & 17 [15 to 19$]$ & $<0.001$ & $-3[-4$ to -2$]$ \\
\hline Tidal volume, $\mathrm{ml}$ & 431 [359 to 498] & $424[379$ to 481$]$ & 0.478 & $-11[-43$ to -21$]$ \\
\hline Tidal volume, ml/kg & $6.9[6.0$ to 7.9$]$ & $6.9[5.7$ to to 7.9$]$ & 0.517 & $-0.16[-0.65$ to 0.33$]$ \\
\hline Minute ventilation, $1 / \min$ & $8.6[7.3$ to 10.6$]$ & $7.7[6.6$ to 8.6$]$ & $<0.001$ & $-1.4[-1.9$ to -0.8$]$ \\
\hline $\mathrm{PaO}_{2} / \mathrm{FiO}_{2}$ ratio, mmHg & 166 [136 to 224$]$ & 314 [232 to 398] & $<0.001$ & 138 [108 to 169$]$ \\
\hline $\mathrm{PaO}_{2}, \mathrm{mmHg}$ & 114 [90 to 141] & 206 [143 to 270] & $<0.001$ & $95[74$ to 116$]$ \\
\hline $\mathrm{PaCO}_{2}, \mathrm{mmHg}$ & 38 [3 to 42$]$ & 39 [37 to 41$]$ & 0.029 & $1.3[0.1$ to 2.5$]$ \\
\hline Ventilatory ratio & $1.4[1.3$ to 1.6$]$ & $1.3[1.1$ to 1.5$]$ & $<0.001$ & $-0.16[-0.25$ to -0.07$]$ \\
\hline Estimated dead-space fraction, $\%$ & $41[3$ to 49$]$ & 32 [23 to 39$]$ & $<0.001$ & $-9[-14$ to -5$]$ \\
\hline
\end{tabular}

Cl confidence interval, bpm breaths per minute

Data are presented as median [interquartile range] for continuous values unless otherwise specified

${ }^{\dagger}$ Supine Position taken as reference
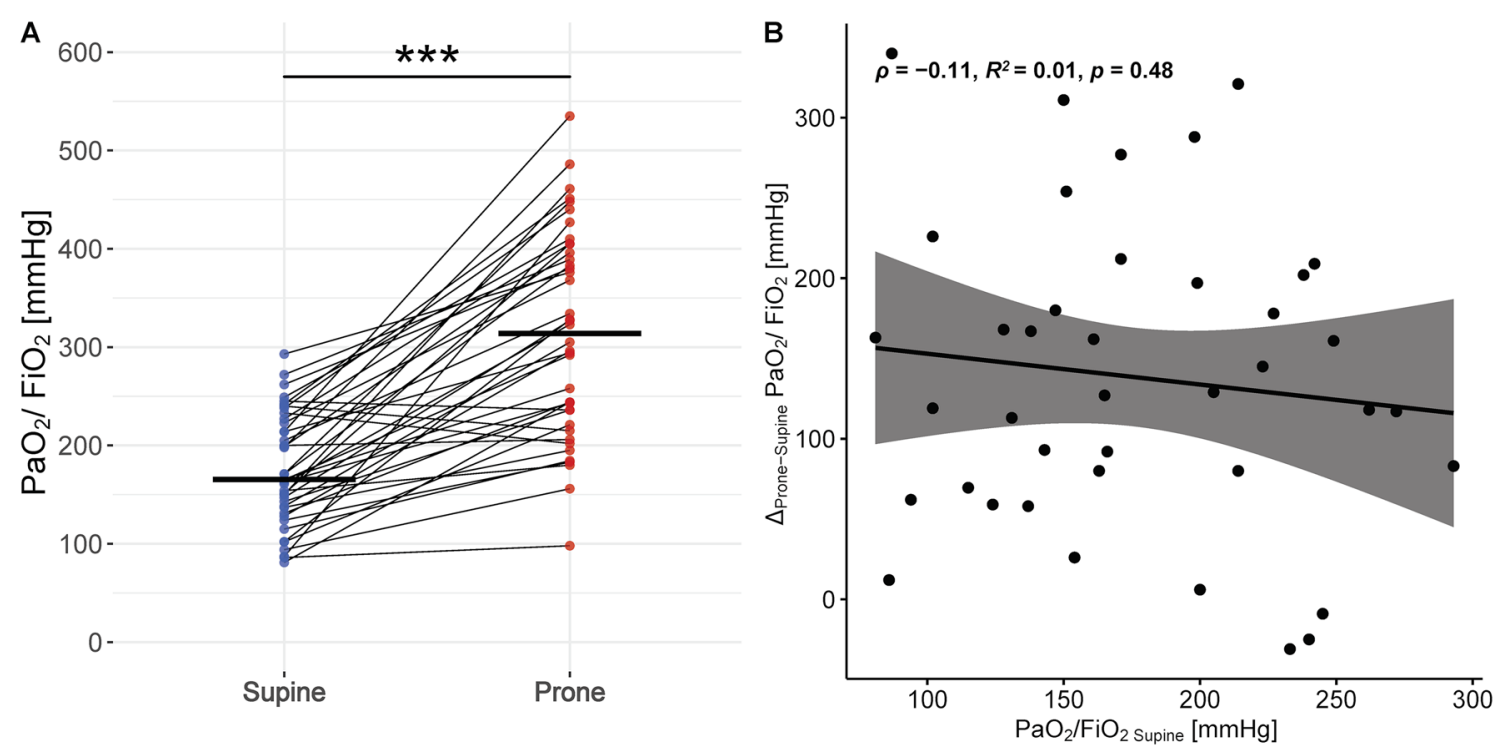

Fig. 2 A Change in $\mathrm{PaO}_{2} / \mathrm{FiO}_{2}$ Ratio from supine to prone position. Individual patient measurements are represented by dots (blue representing supine and red prone position, respectively), thin lines connect pairs of individual patient measurements (supine - prone), and thick horizontal lines

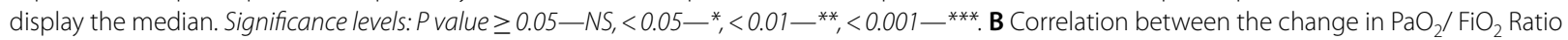
from supine to prone position and its respective value in supine position. The scatter-plot represents individual patient measurement-pairs, the black line displays the fitted linear regression, and the shaded gray area depicts its $95 \%$ Confidence Interval. $\rho$-Pearson correlation coefficient, $p$ - $P$ value

the $\mathrm{mPTP}$ and the WOB decreased from 152 [104-197] to 118 [90-150] $\mathrm{cmH}_{2} \mathrm{O} / \mathrm{min}$ and from 146 [120-185] vs 114 [95-151] $\mathrm{cmH}_{2} \mathrm{O} * \mathrm{~L} / \mathrm{min}$, respectively (Table 3, Figs. 3 and 4). Thirty-three (83\%) patients experienced a reduction in the WOB from supine to prone position, while $26(65 \%)$ experienced a reduction of greater than or equal to $10 \%$. The reduction in the WOB was highly correlated to the baseline in supine position, which was the only marker of inspiratory effort, among esophageal pressure swing, dynamic transpulmonary pressure and modified pressure time product, with prognostic capacity to predict a reduction in the same $(p<0.001)$ (Fig. 3, Additional file 1: Fig. S4). The respiratory rate in supine position was not correlated to the reduction in the WOB from supine to prone position (Additional file 1: Fig. S5).

The MPTP and the WOB were not related to the CT lung anatomical characteristics (lung gas volume and lung weight) (Additional file 1: Figs. S6-S9). In addition, 
Table 3 Extended respiratory mechanics and clinical assessment of the study population during supine position and prone position

\begin{tabular}{|c|c|c|c|c|}
\hline & $\begin{array}{l}\text { Supine } \\
N=40\end{array}$ & $\begin{array}{l}\text { Prone } \\
N=40\end{array}$ & $p$ & Mean difference ${ }^{\dagger}[95 \% \mathrm{Cl}]$ \\
\hline Esophageal pressure swing, $\mathrm{cmH}_{2} \mathrm{O}$ & $-7[-9$ to -5$]$ & $-6[-9$ to -5$]$ & 0.306 & $0.4[-0.4$ to 1.1$]$ \\
\hline Dynamic transpulmonary pressure, $\mathrm{cmH}_{2} \mathrm{O}$ & $17[14$ to 19$]$ & $16[14$ to 18$]$ & 0.34 & $-0.4[-1.1$ to 0.4$]$ \\
\hline Modified pressure-time product, $\mathrm{cmH}_{2} \mathrm{O} / \mathrm{min}$ & 152 [104 to 197] & 118 [90 to 150$]$ & $<0.001$ & $-33[-47$ to -19$]$ \\
\hline Work of breathing, $\mathrm{cmH}_{2} \mathrm{O} * \mathrm{~L} / \mathrm{min}$ & $146[120$ to 185$]$ & 114 [95 to 151$]$ & $<0.001$ & $-27[-38$ to -17$]$ \\
\hline $\begin{array}{l}\text { Borg Dyspnea Scale } \\
0 \text {-none } \\
1 \text {-very light } \\
\text { 2-light } \\
\text { 3-moderate } \\
\text { 4-rather intense }\end{array}$ & $\begin{array}{l}29(72) \\
3(8) \\
5(12) \\
1(2) \\
2(5)\end{array}$ & $\begin{array}{l}37(92) \\
2(5) \\
1(2) \\
0(0) \\
0(0)\end{array}$ & 0.005 & $-0.5[-0.8$ to -0.2$]$ \\
\hline $\begin{array}{l}\text { Non-invasive Work of Breathing Scale } \\
1 \\
2 \\
3 \\
4\end{array}$ & $\begin{array}{l}20(50) \\
12(30) \\
5(12) \\
3(8)\end{array}$ & $\begin{array}{l}31(78) \\
8(20) \\
1(2) \\
0(0)\end{array}$ & 0.001 & $-0.5[-0.9$ to -0.2$]$ \\
\hline
\end{tabular}

$\mathrm{Cl}$ confidence interval

Data are presented as median [interquartile range] for continuous values unless otherwise specified

t Supine Position taken as reference
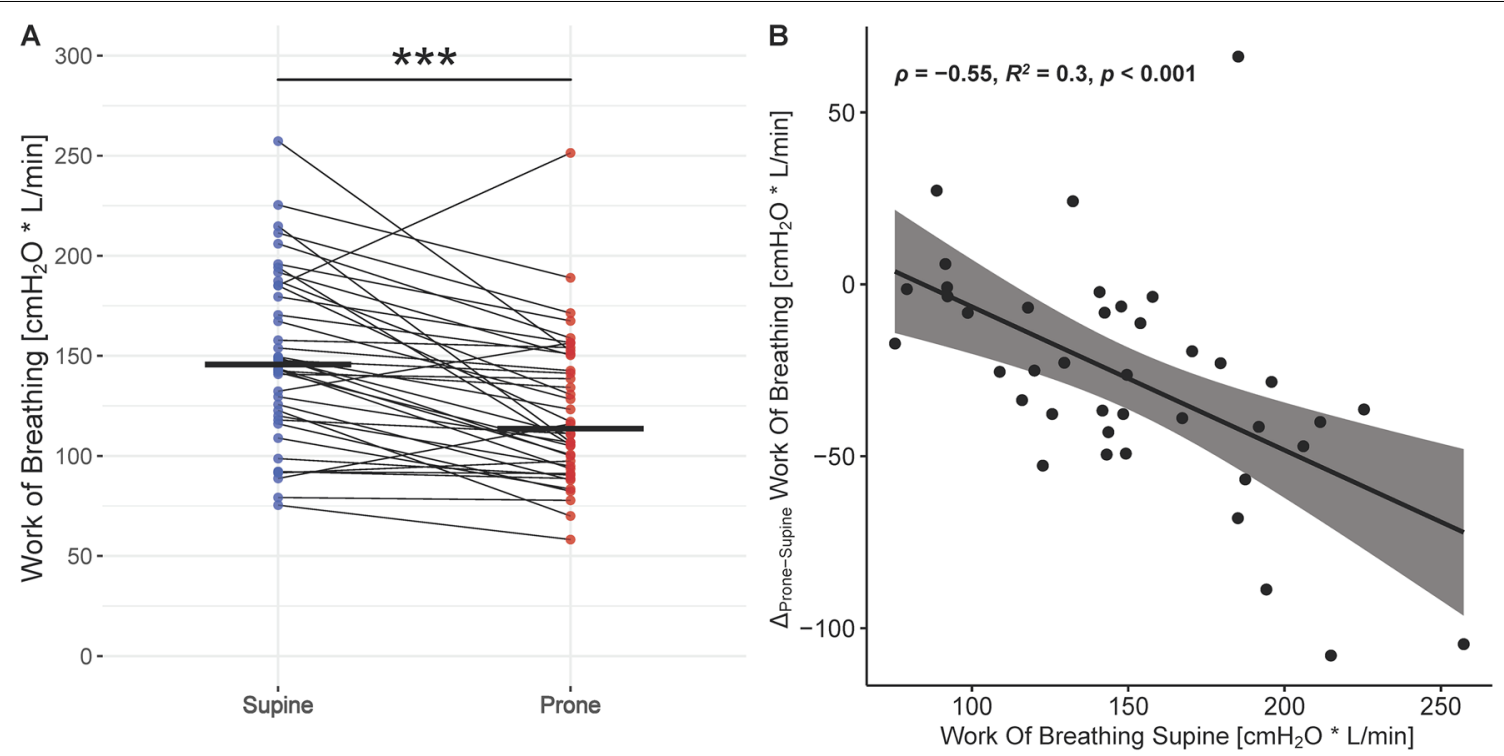

Fig. 3 A Change in Work of Breathing from supine to prone position. Individual patient measurements are represented by dots (blue representing supine and red prone position, respectively), thin lines connect pairs of individual patient measurements (supine — prone), and thick horizontal lines display the median. Significance levels: $P$ value $\geq 0.05-N S,<0.05-{ }^{*},<0.01$ * $^{*},<0.001-{ }^{* * *}$. B Correlation between the change in Work of Breathing from supine to prone position and its respective value in supine position. The scatter-plot represents individual patient measurement-pairs, the black line displays the fitted linear regression, and the shaded gray area depicts its $95 \%$ Confidence Interval. $\rho$ —Pearson correlation coefficient, $p$ — $P$ value

the CT lung anatomical characteristics were not predictive for the physiological response to proning (Additional file 1: Figs. S10-S13).

Twenty-seven patients reported a sensation of dyspnea in supine position, assessed by the Borg scale, ranging from light to rather intense, which notably decreased and disappeared in all patients but three patients after initiating prone position $(p=0.005)$ (Table 3, Additional file 1: Fig. S14). The patient 

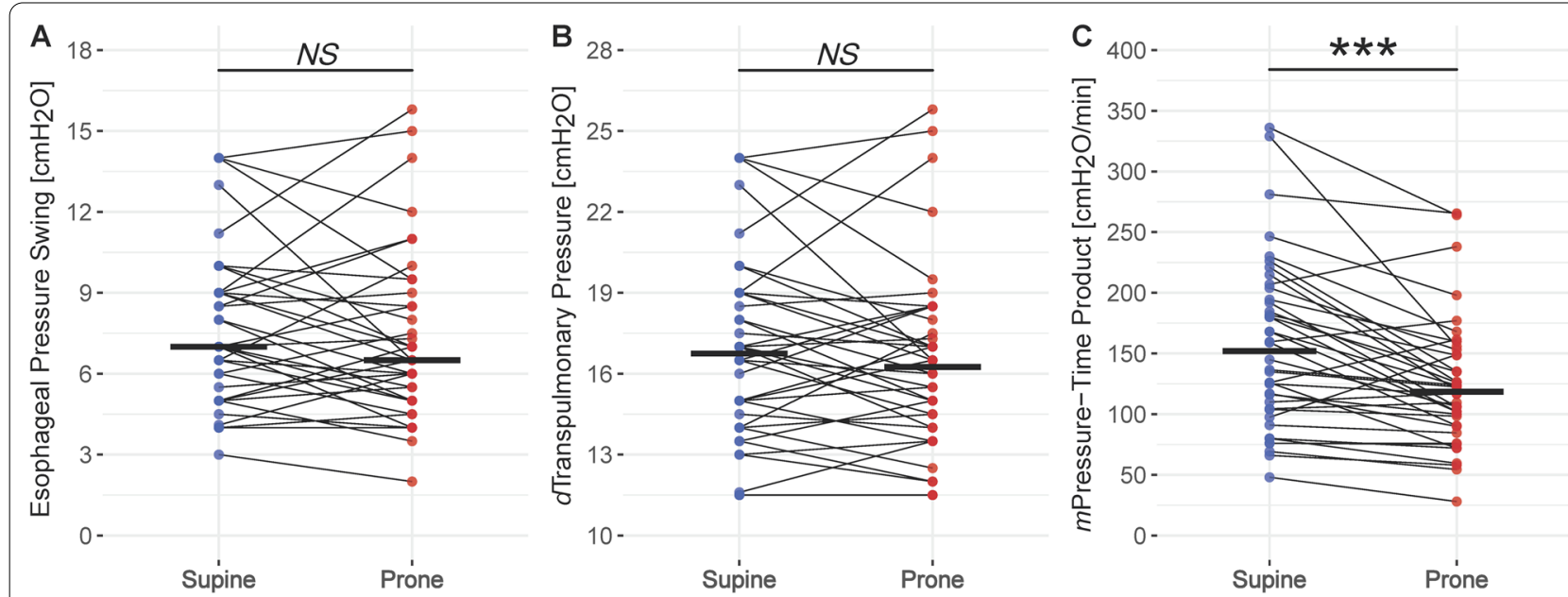

Fig. 4 Changes in Esophageal Pressure Swing (A), dynamic Transpulmonary Pressure (B) and modified Pressure-Time Product (C) between supine and prone position. Individual patient measurements are represented by dots (blue representing supine and red prone position, respectively), thin lines connect pairs of individual patient measurements (supine-prone), and thick horizontal lines display the median. Significance levels: $P$ value $\geq 0.05-N S,<0.05$ - $^{*},<0.01$ — $^{*},<0.001$ - $^{* * *}$

dyspnea sensation was neither related to the MPTP nor to the WOB (Additional file 1: Fig. S15).

Changes in Hemodynamics between supine and prone position are shown in Additional file 1: Table S2. Subgroup analyses stratifying patients by $\mathrm{PaO}_{2} / \mathrm{FiO}_{2}$ ratio, $\Delta$ Pes, dynamic lung compliance (using median value $64 \mathrm{ml} / \mathrm{cmH}_{2} \mathrm{O}$ ) and sensation of dyspnea, in supine position, did not reveal any subgroups with a higher benefit from proning (Additional file 1: Tables S3-S6).

\section{Outcome}

Among the 40 enrolled patients, 7 (18\%) required endotracheal intubation and invasive mechanical ventilation, and 4 of these (53\%) died within the 28 days ensuing study inclusion.

\section{Discussion}

This study, evaluating the effect of awake prone position in CARDS patients treated with helmet CPAP showed that prone position was associated with: (1) a reduction in the work of breathing, (2) an improvement in oxygenation in $85 \%$ of the patients, and (3) a reduced sensation of dyspnea in all patients.

COVID-19 pneumonia is characterized by the presence of hypoxemia, bilateral lung infiltrates and microvascular thrombosis within the lung vasculature, contributing to a profound ventilation-perfusion mismatch $[33,34]$. Thus, COVID-19, in its most severe expression, is characterized by the same pathophysiologic characteristics that are pathognomonic of ARDS. Awake prone position in non-intubated spontaneously breathing patients with acute respiratory failure, has been suggested to improve oxygenation and was feasible in up to $95 \%$ of patients [35, 36]. Several small observational studies in patients suffering COVID-19, have reported similar results in awake spontaneous breathing patients, leading to a recent consensus statement for the management of COVID-19 pneumonia having agreed on the role of prone position as adjunct therapy for the treatment of patients requiring supplement oxygenation to maintain oxygen saturation above $90 \%[12,14,15]$.

In addition to prone position, non-invasive respiratory support, such as HFNC, helmet CPAP and pressure support have been applied both to ameliorate gas exchange and to reduce the inspiratory effort. The combination of prone position and non-invasive respiratory support has been reported to ameliorate the oxygenation in the majority of the studies $[12,14,16]$. The largest series published by Coppo et al. [12], which enrolled 56 patients most of them with helmet CPAP, showed that oxygenation improved on average by more than $50 \%$. In the present study the oxygenation similarly improved, independently of their baseline degree of hypoxemia, just after $3 \mathrm{~h}$ of pronation. This suggests that pronation can be used as an effective strategy capable to ameliorate gas exchange as a rescue or long-term treatment.

Several beneficial mechanisms associated with prone position previously described both in acute respiratory failure and in ARDS, could be also found in patients suffering CARDS [37]. In line with previous descriptions, in the early phase of the disease, the lung weight and lung gas volume of patients with CARDS was approximately half and double, respectively, to that observed in classic ARDS [38]. In addition, the amount 
of non-aerated and poorly aerated lung tissue was quite low. This may indicate that the impairment of oxygenation in the early stage of CARDS is mainly governed by an impairment of the lung perfusion due to a pronounced endothelitis and microvascular thrombosis $[39,40]$. Although we did not measure lung perfusion, the improvement in oxygenation and dead space associated with prone position could be mainly an effect of pulmonary ventilation and perfusion redistribution [34, $37,41]$.

In addition to hypoxemia, CARDS is characterized by vigorous breathing efforts and a high respiratory rate [34]. The strong inspiratory efforts generate high levels of work of breathing and thus, excessive stress and strain to the lung parenchyma, increasing pulmonary edema and exacerbating the lungs injury. These factors in addition to the natural course of lung disease, if not corrected, might promote muscular exhaustion and a deterioration of the lungs function, frequent causes of treatment failure [42].

To date, no data exists on the effects of awake prone position with helmet CPAP on the work of breathing in CARDS. In the present study the inspiratory effort exerted by the respiratory muscles assessed by means of the changes in esophageal pressure and dynamic transpulmonary pressure did not vary between supine and prone position, while the modified pressure time product and work of breathing significantly decreased. These beneficial effects were related mainly to a reduction in respiratory rate, while the tidal volume did not change, thus arguing against a significant change in pulmonary viscoelastic properties, or alveolar recruitment, and diaphragm position and function, between supine and prone position. Furthermore, the reduction in work of breathing was correlated to the amount of work of breathing in supine position, suggesting a higher utility of prone position in patients presenting elevated inspiratory efforts [43].

It has been reported that between 15 and $31 \%$ of spontaneously breathing and non-invasively respiratory supported patients suffering COVID-19 subjectively perceive dyspnea [12, 44]. In the present study $32 \%$ of the patients described the presence of dyspnea, ranging from light to moderately severe according to the Borg dyspnea scale. Most importantly, dyspnea was not related to the severity of hypoxemia, level of carbon dioxide or work of breathing, this could suggest a blunting of the respiratory centers by SARS-COV-2 as has been previously suggested $[33,45]$. A similar dissociation between the comfort of breathing and work of breathing has been previously described in patients suffering ARDS during the weaning phase from invasive mechanical ventilation [28]. Interestingly, prone position was associated with an improved comfort of breathing.
Prone position delivered concomitantly to helmet CPAP thus presents unique advantages regarding improvements in gas exchange and a reduction in the work of breathing, while its impact on endotracheal intubation and invasive mechanical ventilation requirements nevertheless remain unclear $[15,23]$.

\section{Limitations}

Possible limitations of this study are: (1) long term effects of prone position and persistency of effects after returning to supine position are unclear, (2) trans-diaphragmatic pressure was not measured, thus the possible effect of expiratory muscle activity on the measured pressure cannot be assessed, (3) due to the study design, effects of prone position on clinically relevant outcomes could not be evaluated, (4) prone position was not randomized.

In conclusion, awake prone position in addition to helmet CPAP may be offered to CARDS patients to improve oxygenation and reduce WOB. However, a strict clinical evaluation should prevail, to prevent delays in endotracheal intubation and provision of invasive mechanical ventilation.

\section{Abbreviations \\ ARDS: Acute respiratory distress syndrome; CARDS: COVID-19-associated ARDS; Cl: Confidence interval; COVID-19: Coronavirus 2019 disease; CPAP: Continuous positive airway pressure; CT: Computer tomography; $\triangle \mathrm{Pes}$ : Esophageal pressure swing; dTPP: Dynamic transpulmonary pressure; HACOR: Heart Rate, Acidosis, Consciousness, Oxygenation, Respiratory Rate; MPTP: Modified pressure time product; PEEP: Positive end-expiratory pressure; PSILI: Patient self-inflicted lung injury; SAPS II: Simplified Acute Physiology Score; SOFA: Sequential Organ Failure Assessment; VILI: Ventilation induced lung injury; WOB: Work of breathing.}

\section{Supplementary Information}

The online version contains supplementary material available at https://doi. org/10.1186/s13613-021-00967-6.

Additional file 1. Tables S1-S6, Annex S1 and Figures S1-S15.

\section{Acknowledgements}

The authors are grateful to all patients and their families who agreed to participate in this study. We also thank all the physicians and nurses involved in the clinical management of COVID-19 patients in the Hospital ASST Santi Paolo e Carlo of Milan.

\section{Authors' contributions}

DC, EC, SC designed the study, DC, EC, SCB, MP, SC, CG, conducted the study and enrolled the patients, PDWG analyzed the data, DC, PDWG, EC interpreted the data and wrote the first draft of the manuscript, all the authors reviewed the final draft of the manuscript and approved its submission. All authors read and approved the final manuscript.

\section{Funding}

Support was provided solely from institutional and/or departmental sources.

\section{Availability of data and materials}

The data sets used and/or analysed during the current study are available from the corresponding author on reasonable request. 


\section{Declarations}

\section{Ethics approval and consent to participate}

The study was approved by the Institutional Review board of the Hospital ASST Santi Paolo e Carlo (Comitato Etico inter-aziendale Milano Area 1, protocol number 0008332) and informed consent was obtained according to Italian regulations.

\section{Consent for publication}

Patients and/or legal representatives gave written consent to participating in the study and for their anonymous data to be included in publications.

\section{Competing interests}

The authors declare that they have no competing interests.

\section{Author details}

${ }^{1}$ Department of Anesthesia and Intensive Care, ASST Santi Paolo E Carlo, San Paolo University Hospital, Via A. di Rudinì 8, Milan, Italy. ${ }^{2}$ Department of Health Sciences, University of Milan, Milan, Italy. ${ }^{3}$ Coordinated Research Center On Respiratory Failure, University of Milan, Milan, Italy. ${ }^{4}$ Institute of Intensive Care Medicine, University Hospital of Zurich, Zurich, Switzerland.

Received: 25 August 2021 Accepted: 5 December 2021 Published online: 20 December 2021

\section{References}

1. Grasselli G, Zangrillo A, Zanella A, et al. Baseline characteristics and outcomes of 1591 patients infected with SARS-CoV-2 admitted to ICUs of the Lombardy Region, Italy. JAMA. 2020;323:1574-81.

2. Radovanovic D, Santus P, Coppola S, et al. Characteristics, outcomes and global trends of respiratory support in patients hospitalized with COVID19 pneumonia: a scoping review. Minerva Anesthesiol. 2021. https://doi. org/10.23736/S03759393.20.14458-4.

3. Radovanovic D, Coppola S, Franceschi E, et al. Mortality and clinical outcomes in patients with COVID-19 pneumonia treated with non-invasive respiratory support: a rapid review. J Crit Care. 2021;65:1-8.

4. Huang C, Wang Y, Li X, et al. Clinical features of patients infected with 2019 novel coronavirus in Wuhan, China. Lancet. 2020;395:497-506.

5. Raoof S, Nava S, Carpati C, et al. High-flow, noninvasive ventilation and awake (nonintubation) proning in patients with coronavirus disease 2019 with respiratory failure. Chest. 2020;158:1992-2002.

6. Gattinoni L, Taccone P, Carlesso E, et al. Prone position in acute respiratory distress syndrome. Rationale, indications, and limits. Am J Respir Crit Care Med. 2013;188:1286-93.

7. Guérin C, Albert RK, Beitler J, et al. Prone position in ARDS patients: why, when, how and for whom. Intensive Care Med. 2020;46:2385-96.

8. Alhazzani W, Evans L, Alshamsi F, et al. Surviving sepsis campaign guidelines on the management of adults with coronavirus disease 2019 (COVID-19) in the ICU: first update. Crit Care Med. 2021;49:e219-34.

9. Ferrando C, Suarez-Sipmann F, Mellado-Artigas R, et al. Clinical features, ventilatory management, and outcome of ARDS caused by COVID-19 are similar to other causes of ARDS. Intensive Care Med. 2020;46:2200-11.

10. Weiss TT, Cerda F, Scott JB, et al. Prone positioning for patients intubated for severe acute respiratory distress syndrome (ARDS) secondary to COVID-19: a retrospective observational cohort study. Br J Anaesth. 2021;126:48-55.

11. Langer T, Brioni M, Guzzardella A, et al. Prone position in intubated, mechanically ventilated patients with COVID-19: a multi-centric study of more than 1000 patients. Crit Care. 2021;25:128.

12. Coppo A, Bellani G, Winterton D, et al. Feasibility and physiological effects of prone positioning in non-intubated patients with acute respiratory failure due to COVID-19 (PRON-COVID): a prospective cohort study. Lancet Respir Med. 2020;8:765-74.

13. Sartini C, Tresoldi M, Scarpellini $P$, et al. Respiratory parameters in patients with COVID-19 after using noninvasive ventilation in the prone position outside the intensive care unit. JAMA. 2020;323:2338-40.

14. Paternoster $G$, Sartini C, Pennacchio E, et al. Awake pronation with helmet continuous positive airway pressure for COVID-19 acute respiratory distress syndrome patients outside the ICU: a case series. Med Intensiva. 2020. https://doi.org/10.1016/j.medin.2020.08.008.

15. Touchon F, Trigui Y, Prud'homme E, et al. Awake prone positioning for hypoxaemic respiratory failure: past, COVID-19 and perspectives. Eur Respir Rev. 2021;30:210022.

16. Pavlov I, He H, McNicholas B, et al. Awake prone positioning in non-intubated patients with acute hypoxemic respiratory failure due to COVID-19: a systematic review of proportional outcomes comparing observational studies with and without awake prone positioning in the setting of COVID-19. Resp Care. 2021. https://doi.org/10.4187/respcare.09191.

17. Kaur R, Vines DL, Mirza S, et al. Early versus late awake prone positioning in non-intubated patients with COVID-19. Crit Care. 2021;25(1):340. https://doi.org/10.1186/s13054-021-03761-9.

18. Ehrmann S, Li J, Ibarra-Estrada M, Perez Y, et al. Awake Prone Positioning Meta-Trial Group. Awake prone positioning for COVID-19 acute hypoxaemic respiratory failure: a randomised, controlled, multinational, open-label meta-trial. Lancet Respir Med. 2021. https://doi.org/10.1016/ S2213-2600(21)00356-8.

19. Marini JJ, Gattinoni L. Management of COVID-19 respiratory disease. JAMA. 2020;323:2329-30.

20. Grieco DL, Menga LS, Raggi V, et al. Physiological comparison of highflow nasal cannula and helmet noninvasive ventilation in acute hypoxemic respiratory failure. Am J Respir Crit Care Med. 2020;201:303-12.

21. Grieco DL, Menga LS, Cesarano M, et al. Effect of helmet noninvasive ventilation vs high-flow nasal oxygen on days free of respiratory support in patients with COVID-19 and moderate to severe hypoxemic respiratory failure: the HENIVOT randomized clinical trial. JAMA. 2021;325:1731-43.

22. Tonelli R, Fantini R, Tabbì L, et al. Early inspiratory effort assessment by esophageal manometry predicts noninvasive ventilation outcome in de novo respiratory failure. A Pilot Study. Am J Respir Crit Care Med. 2020;202:558-67.

23. Tonelli R, Pisani L, Tabbì L, et al. Early awake proning in critical and severe COVID-19 patients undergoing noninvasive respiratory support: a retrospective multicenter cohort study. Pulmonology. 2021. https://doi.org/10. 1016/j.pulmoe.2021.03.002.

24. Duan J, Han X, Bai L, et al. Assessment of heart rate, acidosis, consciousness, oxygenation, and respiratory rate to predict noninvasive ventilation failure in hypoxemic patients. Intensive Care Med. 2017:43:192-9.

25. Charlson ME, Pompei P, AlesL K, et al. A new method of classifying prognostic comorbidity in longitudinal studies: development and validation. Chronic Dis. 1987;40:373-83.

26. Chiumello D, Caccioppola A, Pozzi T, et al. The assessment of esophageal pressure using different devices: a validation study. Minerva Anestesiol. 2020;86:1047-56

27. Williams GW, George CA, Harvey BC, et al. A comparison of measurements of change in respiratory status in spontaneously breathing volunteers by the ExSpiron Noninvasive Respiratory Volume Monitor Versus the Capnostream Capnometer. Anesth Analg. 2017;124:120-6.

28. Chiumello D, Pelosi $\mathrm{P}$, Croci $M$, et al. The effects of pressurization rate on breathing pattern, work of breathing, gas exchange and patient comfort in pressure support ventilation. Eur Respir J. 2001;18:107-14.

29. Apigo M, Schechtman J, Dhliwayo N, et al. Development of a work of breathing scale and monitoring need of intubation in COVID-19 pneumonia. Crit Care. 2020;24:477.

30. Chiumello D, Mongodi S, Algieri l, et al. Assessment of lung aeration and recruitment by $\mathrm{CT}$ scan and ultrasound in acute respiratory distress syndrome patients. Crit Care Med. 2018;46:1761-8.

31. Coppola S, Davide Chiumello D, Busana M, et al. Role of total lung stress on the progression of early COVID-19 pneumonia. Intensive Care Med. 2021;47(10):1130-9. https://doi.org/10.1007/s00134-021-06519-7 (Epub 2021 Sep 16).

32. L'Her E, Deye N, Lellouche F, et al. Physiologic effects of noninvasive ventilation during acute lung injury. Am J Respir Crit Care Med. 2005:172:1112-8.

33. Tobin MJ, Laghi F, Jubran A. Why COVID-19 silent hypoxemia is baffling to physicians. Am J Respir Crit Care Med. 2020;202:356-60.

34. Tobin MJ. Does making a diagnosis of ARDS in patients with coronavirus disease 2019 matter? Chest. 2020;158:2275-7.

35. Scaravilli V, Grasselli G, Castagna L, et al. Prone positioning improves oxygenation in spontaneously breathing nonintubated patients with 
hypoxemic acute respiratory failure: a retrospective study. J Crit Care. 2015:30:1390-4.

36. Yoshida T, Tanaka A, Roldan R, et al. Prone position reduces spontaneous inspiratory effort in patients with acute respiratory distress syndrome: a bicenter study. Am J Respir Crit Care Med. 2021;203:1437-40.

37. Zarantonello F, Andreatta G, Sella N, et al. Prone position and lung ventilation and perfusion matching in acute respiratory failure due to COVID-19. Am J Respir Crit Care Med. 2020;202:278-9.

38. Gattinoni L, Caironi $P$, Cressoni $M$, et al. Lung recruitment in patients with the acute respiratory distress syndrome. N Engl J Med. 2006;354:1775-86.

39. Ackermann $\mathrm{M}$, Verleden $\mathrm{SE}$, Kuehnel $\mathrm{M}$, et al. Pulmonary vascular endothelilitis, thrombosis, and angiogenesis in Covid-19. N Engl J Med. 2020:383:120-8.

40. Gattinoni L, Chiumello D, Caironi P, et al. COVID-19 pneumonia: different respiratory treatments for different phenotypes? Intensive Care Med. 2020;46:1099-102.

41. Perier F, Tuffet S, Maraffi T, et al. Effect of positive end-expiratory pressure and proning on ventilation and perfusion in COVID-19 acute respiratory distress syndrome. Am J Respir Crit Care Med. 2020;202:1713-7.

42. Cruces $\mathrm{P}$, Retamal J, Hurtado DE, et al. A physiological approach to understand the role of respiratory effort in the progression of lung injury in SARS-CoV-2 infection. Crit Care. 2020;24(1):494. https://doi.org/10.1186/ s13054-020-03197-7.

43. Baudin F, Emeriaud G, Essouri S, et al. Physiological effect of prone position in children with severe bronchiolitis: a randomized cross-over study (BRONCHIO-DV). J Pediatr. 2019;205:112-9.

44. Busana M, Gasperetti A, Giosa L, et al. Prevalence and outcome of silent hypoxemia in COVID-19. Minerva Anestesiol. 2021;87:325-33.

45. Bulfamante G, Chiumello D, Canevini MP, et al. First ultrastructural autoptic findings of SARS-Cov- 2 in olfactory pathways and brainstem. Minerva Anesthesiol. 2020;86:678-9.

\section{Publisher's Note}

Springer Nature remains neutral with regard to jurisdictional claims in published maps and institutional affiliations.

\section{Submit your manuscript to a SpringerOpen ${ }^{0}$ journal and benefit from:}

- Convenient online submission

- Rigorous peer review

- Open access: articles freely available online

- High visibility within the field

- Retaining the copyright to your article

Submit your next manuscript at $\gg$ springeropen.com 